\title{
Association of Cytokine Gene Polymorphisms with Gastritis in a Kazakh Population
}

\author{
Gulmira Nigmetzhanovna Kulmambetova ${ }^{1 *}$, Meruert Kuatbekovna Imanbekova ${ }^{1}$, \\ Andrey Alexeevich Logvinenko², Adilbek Temirzhanovich Sukashev², Maxim \\ Leonidovich Filipenko ${ }^{3}$, Erlan Mirhaidarovich Ramanculov ${ }^{1}$
}

\begin{abstract}
Background: Gastritis and gastric cancer are the most common diseases in the Kazakh population. Polymorphisms in genes coding of cytokines have been played important role with gastric disease risk. The risk alleles of cytokines in patients with gastritis can predict the risk of developing gastric cancer. The aim of this study was to investigate cytokine gene polymorphisms as risk factors for the development of gastritis in a case-control study with gastritis patients and healthy individuals from the Kazakh ethnic group, living in North Kazakhstan. Materials and Methods: The polymerase chain reaction followed by direct sequencing were used for detection of two functional polymorphisms in the IL1 gene family, and TaqMan SNP Genotyping Assay Sets were applied for three potentially functional polymorphisms in the IL10 gene, and one in the TNFA promoter. Results: Association analysis of studied allelic variants and the development of gastritis in $\mathrm{H}$. pyloripositive patients showed that IL1B $-31 \mathrm{C} / \mathrm{C}$, IL1B -511T/T and IL1RN -2/2 allelic variants were associated with development of gastritis $(\mathrm{OR}=1.8(1.07-3.16), \mathrm{p}=0.025 ; \mathrm{OR}=1.7(1.04-2.99), \mathrm{p}=0.035$, and $\mathrm{OR}=4.92(2.45-9.85)$, p<0.001) respectively. Haplotype $C$-T that combines both homozygous allelic variants of IL1B gene also had a statistically significant association with slightly higher OR (OR: 1.43, 95\% CI: 1.08-1.88). Conclusions: The data from the current study showed that the genotype IL-1B -511T/-31C-IL1-RN-2 and $H$. pylori infection increase risk of gastritis in the Kazakh population. That genotype combination might be a factor increasing the risk of developing gastric cancer.
\end{abstract}

Keywords: Helicobacter pylori - gastritis - gastric cancer - polymorphism - cytokine

Asian Pac J Cancer Prev, 15 (18), 7763-7768

\section{Introduction}

Gastric cancer is the second most common cause of mortality in the world. Gastric inflammation plays crucial roles in the developing of the gastric disease such as gastritis and gastric cancer. Gastritis is an inflammation of the mucous membrane of the stomach, accompanied by degenerative changes. Gastritis is exacerbated by the aberrations in the nutritional status, by spicy and high-fat foods, smoking, stress and the abuse of alcohol. During the inflammation, gastric mucosa becomes thinner and the number of fundic glands is reduced. In addition, infection of stomach with Helicobacter pylori may lead to undesirable consequences.

According to the recent studies, infection with $H$. pylori is a risk factor for the development of gastric cancer (Gehmert et al., 2009). Results from other study indicated that except infection $H$. pylori serum Zink level from antioxidant also might be indicator for damage gastric membrane and decreasing serum Zink level in patients with gastritis increasing the risk of gastric cancer (Zhang et al., 2012). From another study exists evidence that key factor in development of gastric cancer p53 gene intron alterations may contribute gastritis development and early detection of these alterations in precancerous lesions such as gastritis may be useful for prediction of risk developing of gastric cancer (Najjar Sadeghi et al., 2013). Gastric cancer is partly a hereditary disease and according recently study the infection Helicobacter pylori and the stomach lesions such as dysplasia, atrophy and chronic gastritis have been met more frequently in individuals with a family history of gastric cancer (Mansour-Ghanaei et al., 2012). In most cases the infection Helicobacter pylori is asymptomatic. H.pylori infectivity is highly dependent on ethnicity and geographical region (Gehmert et al., 2009; Martinez-Carrillo et al., 2010).

About 2/3 of the world population, including $25 \%$ of population in developed countries, are infected with $H$. pylori. This is due to the widespread use of antibiotics that promotes the spread of antibiotic resistance. In post- 
Gulmira Nigmetzhanovna Kulmambetova et al

Soviet countries, the infection reaches 60-70\%. Although the majority of infected people don't have symptoms of stomach diseases, persistent colonization and chronic inflammation increase the risk of gastritis (Gehmert et al., 2009; Martinez-Carrillo et al., 2010).

H. pylori infection induces the production of a cytokines in the lining of the stomach. The most frequently studied inflammatory-related genes with gastric disease are interleukin family genes such as IL1B, IL1RN, IL10, and tumor necrosis factor-alpha (TNFA), coding for the proteins IL- $1 \beta$, IL-1ra, IL-10 and TNF- $\alpha$, respectively. These cytokines play important role in definition of etiology of gastric diseases. Several studies have shown that the level of IL1B expression can be affected by two allelic variants at positions $-511(\mathrm{~T} / \mathrm{T}, \mathrm{rs} 16944)$ and -31 $(\mathrm{C} / \mathrm{C}, \mathrm{rs} 1143627)$ in the promoter region of the gene. These allelic variants are associated with increased transcription of IL1B. Interleukin 1 beta is a potent inhibitor of gastric acid secretion (Uno et al., 2002). Reduced acidity in the stomach leads to inhomogeneous resettlement of H. pylori from the pylorus to the body of the stomach. Therefore, these polymorphisms can be considered as a potential genetic factor in predisposition to gastritis, which determines the risk of malignant transformation.

A number of studies have demonstrated that the alleles $-511 \mathrm{~T}$ and $-31 \mathrm{C}$ in IL1B gene are associated with high level of cytokines and severe inflammation of the stomach (Kato et al., 2001; Sierra et al., 2008). The antiinflammatory cytokine IL1 receptor antagonist (IL1RN) contains a variable number of 86-bp tandem repeats and 5 different alleles have been detected in intron 2 . The allele 2 has been associated with increased risk of gastric cancer in several studies (El-Omar et al., 2000). IL10 down-regulates cytotoxic response and polymorphisms of IL10 also associated with gastric cancer risk (Kim et al., 2014). Three polymorphisms in the IL10 promoter, such as IL-10-G1082A (rs1800896), -C819T (rs1800871), and C592A (rs1800872), are shown inflammatory response at the transcriptional level (Bidwell et al., 1999). The promoter polymorphism of TNFA-308 play important role in $\mathrm{H}$. pylori-induced gastritis and also has been found to influence the risk of gastric cancer (Bhayal et al., 2013). The current theory describing the risk of atrophic gastritis caused by $H$. pylori infection does not always work in studies performed in different ethnic groups and geographic regions (Santtila et al., 1998; Figueiredo et al., 2002; Peek and Blaser, 2002; Hsu et al., 2004; Garza-Gonzalez et al., 2005; Perez-Perez et al., 2005; Al-Moundhri et al., 2006; Moorchung et al., 2007).

Thus, inflammation is dependent on ethnic and geographical difference that partially explains inconsistent results regarding association between the risk of gastric cancer and H. pylori infection. Although gastritis and gastric cancer is at the top of the list of most common diseases in the Kazakh population, the genetic basis for interindividual variations in the inflammatory response and cytokine production in the context of $H$. pylori infection, have not been studied for Kazakhstan.

The aim of this study was to investigate the association of cytokine gene polymorphisms with an increased risk of gastritis in H. pylori-positive groups in Kazakhs.

\section{Materials and Methods}

\section{Patients}

Five hundreds forty seven individuals participated in the case-control study, including 301 gastritis patients recruited at the National Scientific Medical Center (Astana). The participants' age was between of 13 and 80 years (mean age $42.3 \pm 15.2$ ) and the male to female ratio was $130 / 171$. The control group included 246 people, aged 18 to 74 years (mean age $37.6 \pm 14.2$ male/ female ratio=154/92), with no medical history of stomach diseases. Prior to the study, ethical approval was received from the Ethics Committee of the National Center for Biotechnology. The Ethics Committee approved the informed consent form and questionnaire form designed specifically for the study. Biological material was taken with the informed consent signed by all donors. Both, the control group and the study group were recruited from the same geographical area (North Kazakhstan region). Biopsy samples were taken during a routine fibrogastroscopy. $H$. pylori infection status was determined by imprint gastric cytology using Romanovsky-Giemsa stain.

\section{DNA exstraction}

Extraction of genomic DNA from clinical samples was performed by standard procedures from tissue.

PCR amplification, VNTR analysis and polymorphisms analysis using direct sequencing

All samples were genotyped for the VNTR of IL1RN, IL1 gene, IL10 and TNFA by polymerase chain reaction (PCR) and gel electrophoresis. IL1RN variations were determined using primers described by Tarlow et al. (Tarlow et al., 1993). The PCR conditions were as follows: $95^{\circ} \mathrm{C}$ for $4 \mathrm{~min}$; then 30 cycles of $94^{\circ} \mathrm{C}$ for $30 \mathrm{~s}, 60^{\circ} \mathrm{C}$ for $30 \mathrm{~s}$, and $72^{\circ} \mathrm{C}$ for $40 \mathrm{~s}$; then $72^{\circ} \mathrm{C}$ for $5 \mathrm{~min}$. The obtaining amplicons were analyzed by gel electrophoresis. The alleles 1,2,3,4 and 5 were represent as described by Tarlow et al. (Tarlow et al., 1993), 4,2,5,3 and 686 bp repeats, respectively. The alleles 1 and 2 , also named as long and short, respectively, represent the majority of alleles.

For genotyping IL10 and TNFA polymorphisms was used TaqMan SNP Genotyping Assay Sets and detection was performed according the protocol of manufacturer.

IL 1 B genotyping was performed by PCR using the following primers: (IL511 (rs16944) F 5'-ctgcataccgtatgttctctgcc-3', IL5 11R 5'-ggaatcttcccacttacagatgg-3', IL31 (rs1143627) F 5'-tettttccctttcctttaact-3' and IL31R 5' -agagactccettagcacctagt-3'). Amplification was performed under the following conditions: $95^{\circ} \mathrm{C}$ for 5 min; then 35 cycles of $95^{\circ} \mathrm{C}$ for $40 \mathrm{~s}, 58^{\circ} \mathrm{C}$ for $1 \mathrm{~min}$; then $720 \mathrm{C}$ for $1 \mathrm{~min}$ by using Tetrad 2 thermal cycler (Bio-Rad Laboratories, USA).

PCR products were sequenced on ABI 3730x1 automatic genetic analyzer (Applied Biosystems, USA). The obtained data were analyzed with SeqScape v 2.6 software (Applied Biosystems, USA).

\section{Statistical analysis}

The test for Hardy-Weinberg equilibrium was 
performed using Web program (http://www.oege.org/ software/hwe-mr-calc.shtml) of genotype frequencies in the selected allelic variants. Odds ratios (OR) were calculated by using the formula adjusted for small sample size $(\mathrm{OR}=\mathrm{ad} / \mathrm{bc})$. Confidence interval $(\mathrm{CI})$ at $95 \%$ significance level was also calculated. All calculations were performed using DeFinetti online tool (Institute of Human Genetics, Germany, http://ihg.gsf.de/cgi-bin/hw/ hwa1.pl).

\section{Results}

A total of 547 individuals participated in the study, including 301 patients with gastritis and 246 healthy individuals. Allelic variants the genes of cytokines were determined by direct sequencing.

The allele frequencies, genotype frequencies and statistics summary of association analysis the genes of cytokines are shown in Table 1. There was not found statistically significant association of genotype frequencies from Hardy-Weinberg equilibrium ( $\mathrm{p}=0.05)$ in IL1B -31C position between patients with negative $H$. pylori status and a control group. Here the IL1B -31CC had higher $\mathrm{p}=0.17$ in order to fix significant association. Statistically significant differences in genotype frequencies of polymorphic loci IL1B $-511(\mathrm{C}>\mathrm{T})$ between patients with negative $H$. pylori status and a control group were not identified. However the association analysis of the selected allelic variants with the development of gastritis in $\mathrm{H}$. pylori-positive patients showed that IL1B -31C/C and IL1B $-511 \mathrm{~T} / \mathrm{T}$ were associated with the development of gastritis $(\mathrm{OR}=1.8(1.07-3.16), \mathrm{p}=0.025$ and $\mathrm{OR}=1.7$ (1.04-2.99), $\mathrm{p}=0.035$, respectively (Table 1). Overall, we describe seven genetic variations in the IL1 gene family, IL10, and TNFA gene. The IL1RN VNTR consists of five major alleles in possible genotypes. In our study 108 $(59.0 \%)$ of the patients were carrying the most common genotypes L/L (108/183). The heterozygotes (2/L) and homozygotes $(2 / 2)$ genotypes of the IL1RN gene were shown significant association with gastritis $(\mathrm{OR}=1.91$, $\mathrm{p}=0.01, \mathrm{OR}=3.89, \mathrm{p}<0.001$, respectively) and gastritis with infection $H$. pylori $(\mathrm{OR}=1.75, \mathrm{p}=0.05, \mathrm{OR}=4.92$, $\mathrm{p}<0.001$, respectively) (Table 1 ). The other genotypes of IL10 and TNFA genes were not shown significant association with gastritis in Kazakh population. The genotype distribution is shown in Table 1 .

Haplotype C-T that combines both homozygous allelic variants also had a statistically significant association with slightly higher OR and statistical significance (OR: 1.43, 95\% CI: 1.08-1.88) in H. pylori-positive patients with gastritis and the control group (Table 2).

Genotype frequencies in different ethnic groups are represented in the Table 3.

The frequency of IL1B-511T and IL1B-31C alleles was found to be variable in different ethnic groups (Table 3). The differences in two polymorphisms are statistically

Table 1. Genotype and Allele Distribution of Cytokines Polymorphisms from Patients with Gastritis

\begin{tabular}{|c|c|c|c|c|c|c|c|c|}
\hline \multirow[t]{2}{*}{ Genotype } & & \multicolumn{3}{|c|}{ Negative $H$. pylori Infection } & \multirow[b]{2}{*}{$\mathrm{p}$ value } & \multicolumn{3}{|c|}{ Positive $H$. pylori Infection } \\
\hline & & Controls & Cases & $\mathrm{OR}(95 \% \mathrm{CI})$ & & Cases & $\mathrm{OR}(95 \% \mathrm{CI})$ & $\mathrm{p}$ value \\
\hline \multirow[t]{5}{*}{ IL1B-511 } & $\mathrm{C} / \mathrm{C}$ & $71(28.9)$ & $22(25.9)$ & 1 & & $44(20.4)$ & 1 & \\
\hline & $\mathrm{C} / \mathrm{T}$ & $122(49.6)$ & $39(45.9)$ & $1.03(0.56-1.87)$ & 0.918 & $114(52.8)$ & $1.5(0.95-2.37)$ & 0.076 \\
\hline & $\mathrm{T} / \mathrm{T}$ & $53(21.5)$ & $24(28.2)$ & $1.46(0.74-2.88)$ & 0.272 & $58(26.8)$ & $1.7(1.04-2.99)$ & 0.035 \\
\hline & $\mathrm{C}$ & $264(53.6)$ & $83(48.8)$ & 1 & & $202(46.8)$ & 1 & \\
\hline & $\mathrm{T}$ & $228(46.34)$ & $87(51.2)$ & $1.16(0.66-2.03)$ & 0.59 & $230(53.2)$ & $1.58(1.03-2.44)$ & 0.03 \\
\hline \multirow[t]{5}{*}{ IL1B-31 } & $\mathrm{T} / \mathrm{T}$ & $71(28.9)$ & $22(25.9)$ & 1 & & $46(21.3)$ & 1 & \\
\hline & $\mathrm{C} / \mathrm{T}$ & $129(52.4)$ & $40(47.1)$ & $1.0(0.55-1.81)$ & 0.998 & $115(53.3)$ & $1.3(0.87-2.15)$ & 0.162 \\
\hline & $\mathrm{C} / \mathrm{C}$ & $46(18.7)$ & $23(27)$ & $1.6(0.80-3.22)$ & 0.174 & $55(25.4)$ & $1.8(1.07-3.16)$ & 0.025 \\
\hline & $\mathrm{T}$ & $271(55.1)$ & $84(49.4)$ & 1 & & 207 (47.9) & 1 & \\
\hline & $\mathrm{C}$ & $221(44.9)$ & $86(50.6)$ & $1.16(0.66-2.03)$ & 0.59 & $225(52.1)$ & $1.5(0.97-2.29)$ & 0.06 \\
\hline \multirow[t]{5}{*}{ IL1RN } & $\mathrm{L} / \mathrm{L}$ & $161(78.2)$ & $108(59.0)$ & 1 & & $83(57.2)$ & 1 & \\
\hline & $2 / \mathrm{L}$ & $32(15.5)$ & $41(22.4)$ & $1.91(1.13-3.22)$ & 0.01 & $29(20.0)$ & $1.75(0.99-3.1)$ & 0.05 \\
\hline & $2 / 2$ & $13(6.3)$ & $34(18.6)$ & $3.89(1.96-7.72)$ & $<0.001$ & $33(22.8)$ & $4.92(2.45-9.85)$ & $<0.001$ \\
\hline & $\mathrm{L}$ & $354(85.9)$ & $257(70.2)$ & 1 & & $195(67.2)$ & 1 & \\
\hline & 2 & $58(14.1)$ & $109(29.8)$ & $2.48(1.59-3.87)$ & $<0.001$ & $95(32.8)$ & $2.67(1.67-4.26)$ & $<0.001$ \\
\hline \multirow[t]{5}{*}{ IL10-1082 } & $\mathrm{AA}$ & $133(58.1)$ & $108(65.06)$ & 1 & & $73(65.06)$ & 1 & \\
\hline & GA & $81(36.2)$ & $49(29.52)$ & $0.74(0.50-1.10)$ & 0.18 & $42(29.52)$ & $0.94(0.61-1.44)$ & 0.81 \\
\hline & GG & $16(5.7)$ & $9 \quad(5.42)$ & $0.69(0.32-1.50)$ & 0.39 & $4 \quad(5.42)$ & $0.45(0.15-1.32)$ & 0.16 \\
\hline & A & $347(75.4)$ & $265(79.8)$ & 1 & & $188(79)$ & 1 & \\
\hline & $\mathrm{G}$ & $113(24.6)$ & $67(20.2)$ & $0.73(0.48-1.11)$ & 0.14 & $50(21)$ & $0.86(0.55-1.35)$ & 0.52 \\
\hline \multirow[t]{5}{*}{ IL10-819 } & TT & $50(21.8)$ & $94(12.5)$ & 1 & & $63(12.5)$ & 1 & \\
\hline & $\mathrm{CT}$ & $113(49.3)$ & $98(63.75)$ & $0.46(0.31-0.66)$ & 0 & $69(63.75)$ & $0.48(0.32-0.73)$ & 0 \\
\hline & $\mathrm{CC}$ & $66(28.9)$ & $41(23.75)$ & $0.33(0.21-0.52)$ & 0 & $26(23.75)$ & $0.31(0.18-0.53)$ & 0 \\
\hline & $\mathrm{T}$ & $213(46.5)$ & $286(61.4)$ & 1 & & $195(61.7)$ & 1 & \\
\hline & $\mathrm{C}$ & $245(53.5)$ & $180(38.6)$ & $0.41(0.27-0.62)$ & 0.00002 & $121(38.3)$ & $0.42(0.26-0.65)$ & 0.00012 \\
\hline \multirow[t]{5}{*}{ IL10-592 } & $\mathrm{AA}$ & $57(24.8)$ & $62(28.6)$ & 1 & & $47(28.6)$ & 1 & \\
\hline & $\mathrm{AC}$ & $133(57.8)$ & 155 (71.4) & $1.07(0.69-1.64)$ & 0.75 & $114(71.4)$ & $1.04(0.65-1.64)$ & 0.86 \\
\hline & $\mathrm{CC}$ & $40(17.4)$ & 0 & $0.01(0.00-0.18)$ & 0 & 0 & $0.01(0.00-0.25)$ & 0 \\
\hline & A & $247(53.7)$ & $279(64.3)$ & 1 & & $208(64.6)$ & 1 & \\
\hline & $\mathrm{C}$ & $213(46.3)$ & $155(35.7)$ & $0.82(0.54-1.25)$ & 0.36 & $114(35.4)$ & $0.79(0.50-1.25)$ & 0.33 \\
\hline \multirow[t]{5}{*}{ TNFA-308 } & GG & $143(70.8)$ & $183(82.8)$ & 1 & & $115(82.8)$ & 1 & \\
\hline & GA & $54(26.7)$ & $36(16.3)$ & $0.52(0.32-0.84)$ & 0.01 & $26(16.3)$ & $0.59(0.35-1.01)$ & 0.05 \\
\hline & AA & $5 \quad(2.5)$ & $2(0.9)$ & $0.31(0.06-1.63)$ & 0.15 & $1 \quad(0.9)$ & $0.24(0.02-2.15)$ & 0.17 \\
\hline & $\mathrm{G}$ & $340(84.2)$ & $402(91)$ & 1 & & $256(90.1)$ & 1 & \\
\hline & A & $64(15.8)$ & $40 \quad(9)$ & $0.50(0.31-0.79)$ & 0.003 & $28(9.9)$ & $0.56(0.33-0.95)$ & 0.03 \\
\hline
\end{tabular}




\begin{tabular}{|c|c|c|c|c|c|c|c|c|c|c|}
\hline \multicolumn{7}{|c|}{ Patients with gastritis and control group } & \multicolumn{4}{|c|}{ H. pylori-positive patients with gastritis } \\
\hline-31 & -511 & $\begin{array}{l}\text { the control } \\
\text { group }\end{array}$ & $\begin{array}{c}\text { all } \\
\text { samples }\end{array}$ & $\begin{array}{l}\text { the case } \\
\text { group }\end{array}$ & OR $(95 \% \mathrm{CI})$ & $\mathrm{p}$ value & $\begin{array}{c}\text { all } \\
\text { samples }\end{array}$ & $\begin{array}{l}\text { the case } \\
\text { group }\end{array}$ & OR $(95 \% \mathrm{CI})$ & $\mathrm{p}$ value \\
\hline $\mathrm{T}$ & $\mathrm{T}$ & 033 & 0 & & ) ( & 0 & 4 & & & 0.077 \\
\hline $\mathrm{T}$ & $\mathrm{C}$ & 18 & 7 & 0.480 & Reference haplotype & - & 0.493 & & Reference haplotype & - \\
\hline $\mathrm{C}$ & $\mathrm{T}$ & 0.430 & 0.471 & 0.505 & $1.33(1.38-1.72)$ & $0.024 \mathrm{r}$ & 0.472 & & $1.43(1.08-1.88)$ & 0.01 risk \\
\hline $\mathrm{C}$ & $\mathrm{C}$ & 0.019 & 0.009 & 0.002 & $0.09(0.01-0.71) \quad($ & 0.023 protective & 0.011 & 0.002 & $0.13(0.02-1.01)$ & 0.052 \\
\hline
\end{tabular}

*The frequency of the haplotype in Kazakhs

Table 3. IL1B -511T and IL1B -31C Allele Frequency in Different Ethnic Groups

\begin{tabular}{lcccr}
\hline Ethnic group & IL1B -511*T & $\begin{array}{c}\text { p value } \\
\text { (compared to Kazakhs) }\end{array}$ & IL-1B -31*C & $\begin{array}{c}\text { p value } \\
\text { (compared to Kazakhs) }\end{array}$ \\
\hline Kazakhs $(\mathrm{n}=246)$ & $228(46.3)$ & & $221(44.9)$ & $<0.001$ \\
Caucasians $^{\mathrm{a}}(\mathrm{n}=299)$ & $200(34.6)$ & $<0.001$ & $197(34.8)$ & 0.038 \\
Chinese $^{\mathrm{b}}(\mathrm{n}=508)$ & $454(44.7)$ & 0.544 & $514(50.6)$ & $<0.001$ \\
African-Americans $^{\mathrm{a}}(\mathrm{n}=294)$ & $311(53.4)$ & 0.020 & $335(59.0)$ & \\
\hline
\end{tabular}

${ }^{*}$ (Zabaleta et al., 2008); ${ }^{\text {(He et al., 2011) }}$

significant between the three ethnic groups, the exception there is in IL1B $-511 \mathrm{~T}(\mathrm{p}=0.544)$ between Kazakh and Chinese groups. The alleles IL1B-511T and IL1B-31C more identified in an African-Americans (53.4 and 59.0\%, respectively) than in other groups. In Caucasians IL1B511T and IL1B-31C (34.6 and 34.8\%, respectively) were less than Kazakh group.

\section{Discussion}

The prevalence of gastritis in the studied geographic area of Kazakhstan is $18 \%$ per 100.000 people (www. medinfo.kz). This proportion is significantly lower comparing to $24 \%$ per 100.000 people in 2003 (www. medinfo.kz). Partially, it may be explained by earlier prognosis of the disease and timely treatment. However, there are several regional risk factors for the Kazakh population, such as high colonization with H. pylori, caused by traditional dietary habits. At the same time, the role of genetic differences as a risk factor for the development of gastritis has not previously been investigated in Kazakh ethnic group.

In the present study, the effects of allelic variants of the cytokines on the risk of gastritis in the population of ethnic Kazakhs were examined. In the populations of East Asia and Europe alleles of interleukin-1 beta are associated with an increased risk of atrophic gastritis and gastric cancer (El-Omar et al., 2000; Matsukura et al., 2003; Yamada et al., 2006). A meta-analysis study on the relationship of IL1B polymorphism with the development of precancerous conditions of the stomach was conducted by Peleteiro et al. (Peleteiro et al., 2010). In particular, there is a weak association of the development of gastric epithelial metaplasia in carriers of $\mathrm{T}$ allele at position IL1B-511 (OR=1.86) (Peleteiro et al., 2010). Previously, the association of IL1B-511T/-31C alleles and IL1RN*2 with the risk of gastric cancer has been shown in the European population by El-Omar et al. (El-Omar et al., 2000).

A cohort study on Japanese population has shown that allele IL1B-511T was associated with increased expression of IL1B in the gastric mucosa infected with $H$. pylori (Furuta et al., 2004). Similar experimental findings were made in the study of Chinese population, when the same genotype was associated with gastric atrophy and hypochlorhydria (Yang et al., 2004).

However, the association of gene polymorphism IL1B with the risk of gastric cancer was not found in the Korean population. Lee et al. have not confirmed an association between the polymorphism of IL1B-31 and increased risk of gastric cancer (Lee et al., 2003). Matsukara and colleagues reported that ethnic differences of IL1B gene polymorphism affect the risk of gastric atrophy. On the other hand, no association was found between the polymorphism of the IL1B and the risk of atrophic gastritis in the Thai and Vietnamese populations (Matsukura et al., 2003). There is a higher occurrence of IL1B-511T and IL1B-31C alleles in African-Americans comparing to European population (Zabaleta et al., 2008). Thus, it can be concluded that the relationship between genetic polymorphisms of interleukin-1-beta and inflammation response in the mucous membrane of the stomach is not universal in different ethnic groups.

Differences between ethnic groups can also be seen on a haplotype level. For example, a haplotype that combines both homozygous risk alleles occurs two times more often in the African-Americans than in the Europeans (Zabaleta et al., 2008). In another study, Jie Yang and colleagues conducted haplotype analysis that defined the IL1B$31 \mathrm{~T}$ and $-511 \mathrm{C}$ as risk alleles, while a synergistic effect between the two loci was not found (Yang et al., 2004).

The genetic studies conducted in Asia are scarce, what makes situation less clear. Ryu et al. reported that the polymorphism of IL1B -511 and -31 loci was not associated with $H$. pylori infection and risk of gastric cancer in the Korean population.

In our study, the experimental group based on a status of $H$. pylori infection leads to statistically significant associations of IL1B-511T/T allele $(\mathrm{OR}=1.7, \mathrm{p}=0.035)$, IL1B-31C/C allele $(\mathrm{OR}=1.8, \mathrm{p}=0.025)$, and combination of both alleles with the risk of gastritis.

The results of our study show a minor association of haplotype containing both risk allele T-T and C-C $(p=0.038,0.023$, respectively) with the risk of gastritis 
$(\mathrm{OR}=1.33, \mathrm{p}=0.024)$. The differentiation of patients according to the status of $H$. pylori infection further increases the power of the association of the C-T haplotype $(\mathrm{OR}=1.43$, 95\%CI: $1.08-1.88, \mathrm{p}=0.01)$.

This is not surprising, considering the fact that constant inflammatory response to $H$. pylori infection causes peptic ulcer disease or chronic gastritis. These conditions, in turn, are risk factors for development of adenocarcinoma of the stomach (El-Omar, 2001). At least $1 \%$ of H. pyloripositive gastritis patients will develop gastric cancer (Persson et al., 2011). This process generally depends on the intensity of inflammation and patient's genetic constitution.

A meta-analysis study conducted by Persson et al. indicated an increase in the overall risk of developing the disease in the Asian population in carriers of IL1B-31 T allele (Persson et al., 2011). It can be assumed that the increase of risk is associated with high $H$.pylori infectivity of Asian populations.

Genotypes of the IL10 have presented different results depends on ethnic group. The genotype IL-10-1082G/$819 \mathrm{C} /-592 \mathrm{C}$ was associated with gastric diseases in Asians, while IL-10-1082A/-81T/-592T was linked to gastric disease risk in Caucasians. The racial differences, number of patients enrolled them age, diagnosis, study design may contribute the differences in the results (Kang et al., 2009). Some recently meta-analysis have been shown that IL-10 -819TT genotype may be a protective factor for gastric cancer in Asians (Yu et al., 2013). Moreover study from China has been demonstrated that the IL-10-592 polymorphism is associated with protective effect in non-cardia gastric cancer (Pan et al., 2013). In the present study we did not find the significant association between IL-10 polymorphism and the risk of development gastritis.

TNFA produces the inflammatory response against infection and as IL1B inhibits gastric acid secretion (Garza-Gonzalez et al., 2005). In our study, we investigated the association between TNF- $\alpha-308 \mathrm{G} / \mathrm{A}$ polymorphism and risk to developing to gastritis in a Helicobacter pylori infected Kazakh population. Some case-controls studies have been shown the correlation between TNF- $\alpha$ polymorphism and the risk of gastric cancer. El-Omar et al. observed TNF- $\alpha-308$ AA genotype which linked with an increased risk of non-cardia gastric carcinoma in Hp seropositive individuals $(\mathrm{OR}=2.6)$. Other case-control studies, which were conducted in East Asia did not find significant association between TNF- $\alpha-308$ polymorphism and the risk of gastric cancer. Our results indicate that the TNF- $\alpha-308$ polymorphism does not play important role in risk of development of gastritis in Hp positive Kazakh population. The different results of these studies may be explained by the geographical enigma, which include the genetic heterogeneity and vary gene-environment interactions in the development of gastric diseases in different populations (Zhu et al., 2014).

As a result, our study has shown that the development of gastritis in the Kazakh population is affected by a combination of genotype IL-1B -511T/-31C/IL$1 \mathrm{RN}^{*} 2$ and $H$. pylori infection. It is quite possible, that combination of these factors increases the risk of developing gastric cancer in patients with gastritis.

\section{Acknowledgements}

This study was funded by the Ministry of Education and Science of the Republic of Kazakhstan (grant 0110RK00008). The authors have no conflicts of interest.

\section{References}

Al-Moundhri MS, Al-Nabhani M, Al-Bahrani B, et al (2006). Interleukin-1beta gene (IL-1B) and interleukin 1 receptor antagonist gene (IL-1RN) polymorphisms and gastric cancer risk in an Omani Arab population. Gastric Cancer, 9, 284-90.

Bhayal AC, Krishnaveni D, RangaRao KP, et al (2013). Role of tumor necrosis factor-alpha $-308 \mathrm{G} / \mathrm{A}$ promoter polymorphism in gastric cancer. Saudi J Gastroenterol, 19, 182-6.

Bidwell J, Keen L, Gallagher G, et al (1999). Cytokine gene polymorphism in human disease: on-line databases. Genes Immun, 1, 3-19.

El-Omar EM (2001). The importance of interleukin 1beta in Helicobacter pylori associated disease. Gut, 48, 743-7.

El-Omar EM, Carrington M, Chow WH, et al (2000). Interleukin-1 polymorphisms associated with increased risk of gastric cancer. Nature, 404, 398-402.

Figueiredo C, Machado JC, Pharoah P, et al (2002). Helicobacter pylori and interleukin 1 genotyping: an opportunity to identify high-risk individuals for gastric carcinoma. J Natl Cancer Inst, 94, 1680-7.

Furuta T, Shirai N, Sugimoto M (2004). Controversy in polymorphisms of interleukin-1beta in gastric cancer risks. J Gastroenterol, 39, 501-3.

Garza-Gonzalez E, Bosques-Padilla FJ, El-Omar E, et al (2005). Role of the polymorphic IL-1B, IL-1RN and TNF-A genes in distal gastric cancer in Mexico. Int J Cancer, 114, 237-41.

Gehmert S, Velapatino B, Herrera P, et al (2009). Interleukin-1 beta single-nucleotide polymorphism's $\mathrm{C}$ allele is associated with elevated risk of gastric cancer in Helicobacter pyloriinfected Peruvians. Am J Trop Med Hyg, 81, 804-10.

He BS, Pan YQ, Xu YF, et al (2011). Polymorphisms in interleukin-1B (IL-1B) and interleukin 1 receptor antagonist (IL-1RN) genes associate with gastric cancer risk in the Chinese population. Dig Dis Sci, 56, 2017-23.

Hsu PI, Li CN, Tseng HH, et al (2004). The interleukin-1 RN polymorphism and Helicobacter pylori infection in the development of duodenal ulcer. Helicobacter, 9, 605-13.

Kang JM, Kim N, Lee DH, et al (2009). The effects of genetic polymorphisms of IL-6, IL-8, and IL-10 on Helicobacter pylori-induced gastroduodenal diseases in Korea. J Clin Gastroenterol, 43, 420-8.

Kato S, Onda M, Yamada S, et al (2001). Association of the interleukin-1 beta genetic polymorphism and gastric cancer risk in Japanese. J Gastroenterol, 36, 696-9.

Kim J, Kim Y, Lee KA (2014). Ethnic differences in gastric cancer genetic susceptibility: allele flips of interleukin gene. World J Gastroenterol, 20, 4558-65.

Lee SG, Kim B, Choi W, et al (2003). Lack of association between pro-inflammatory genotypes of the interleukin-1 (IL-1B $-31 \mathrm{C} /+$ and IL-1RN $* 2 / * 2$ ) and gastric cancer/ duodenal ulcer in Korean population. Cytokine, 21, 167-71.

Mansour-Ghanaei F, Joukar F, Baghaei SM, et al (2012). Gastric precancerous lesions in first degree relatives of patients with known gastric cancer: a cross-sectional prospective study in Guilan Province, north of Iran. Asian Pac J Cancer Prev, 13, 1779-82. 
Gulmira Nigmetzhanovna Kulmambetova et al

Martinez-Carrillo DN, Garza-Gonzalez E, Betancourt-Linares $\mathrm{R}$, et al (2010). Association of IL1B -511C/-31T haplotype and Helicobacter pylori vacA genotypes with gastric ulcer and chronic gastritis. BMC Gastroenterol, 10, 126.

Matsukura N, Yamada S, Kato S, et al (2003). Genetic differences in interleukin-1 betapolymorphisms among four Asian populations: an analysis of the Asian paradox between $H$. pylori infection and gastric cancer incidence. J Exp Clin Cancer Res, 22, 47-55.

Moorchung N, Srivastava AN, Gupta NK, et al (2007). Cytokine gene polymorphisms and the pathology of chronic gastritis. Singapore Med J, 48, 447-54.

Najjar Sadeghi R, Damavand B, Vahedi M, et al (2013). Detection of p53 common intron polymorphisms in patients with gastritis lesions from Iran. Asian Pac J Cancer Prev, 14, 91-6.

Pan XF, Yang SJ, Loh M, et al (2013). Interleukin-10 gene promoter polymorphisms and risk of gastric cancer in a Chinese population: single nucleotide and haplotype analyses. Asian Pac J Cancer Prev, 14, 2577-82.

Peek RM, Jr., Blaser MJ (2002). Helicobacter pylori and gastrointestinal tract adenocarcinomas. Nat Rev Cancer, 2, 28-37.

Peleteiro B, Lunet N, Carrilho C, et al (2010). Association between cytokine gene polymorphisms and gastric precancerous lesions: systematic review and meta-analysis. Cancer Epidemiol Biomarkers Prev, 19, 762-76.

Perez-Perez GI, Garza-Gonzalez E, Portal C, et al (2005). Role of cytokine polymorphisms in the risk of distal gastric cancer development. Cancer Epidemiol Biomarkers Prev, 14, 1869-73.

Persson C, Canedo P, Machado JC, et al (2011). Polymorphisms in inflammatory response genes and their association with gastric cancer: A HuGE systematic review and metaanalyses. Am J Epidemiol, 173, 259-70.

Santtila S, Savinainen K, Hurme M (1998). Presence of the IL-1RA allele 2 (IL1RN*2) is associated with enhanced IL-1 beta production in vitro. Scand J Immunol, 47, 195-8.

Sierra R, Une C, Ramirez V, et al (2008). Relation of atrophic gastritis with Helicobacter pylori-CagA(+) and interleukin-1 gene polymorphisms. World J Gastroenterol, 14, 6481-7.

Tarlow JK, Blakemore AI, Lennard A, et al (1993). Polymorphism in human IL-1 receptor antagonist gene intron 2 is caused by variable numbers of an 86-bp tandem repeat. Hum Genet, 91, 403-4.

Uno M, Hamajima N, Ito LS, et al (2002). Helicobacter pylori seropositivity and IL-1B C-31T polymorphism among Japanese Brazilians. Int J Mol Med, 10, 321-6.

Yamada S, Matsuhisa T, Makonkawkeyoon L, et al (2006). Helicobacter pylori infection in combination with the serum pepsinogen I/II ratio and interleukin-1beta-511 polymorphisms are independent risk factors for gastric cancer in Thais. J Gastroenterol, 41, 1169-77.

Yang J, Hu Z, Xu Y, et al (2004). Interleukin-1B gene promoter variants are associated with an increased risk of gastric cancer in a Chinese population. Cancer Lett, 215, 191-8.

Yu Z, Liu Q, Huang C, et al (2013). The interleukin 10 -819C/T polymorphism and cancer risk: a HuGE review and metaanalysis of 73 studies including 15,942 cases and 22,336 controls. OMICS, 17, 200-14.

Zabaleta J, Schneider BG, Ryckman K, et al (2008). Ethnic differences in cytokine gene polymorphisms: potential implications for cancer development. Cancer Immunol Immunother, 57, 107-14.

Zhang WH, Wu XJ, Niu JX, et al (2012). Serum zinc status and Helicobacter pylori infection in gastric disease patients. Asian Pac J Cancer Prev, 13, 5043-6.
Zhu F, Zhao H, Tian X, et al (2014). Association between tumor necrosis factor-alpha rs 1800629 polymorphism and risk of gastric cancer: a meta-analysis. Tumour Biol, 35, 1799-803. 